\title{
A Method: Fornix Depth Measurement in Ophthalmic Socket
}

\author{
Raj Kumar ${ }^{1, *}$, Kavita Bhatnagar ${ }^{1}$, Ashok Kumar Khurana ${ }^{2}$, Naveen Meena ${ }^{1}$ and Himanshu Tripathi ${ }^{1}$ \\ ${ }^{1}$ National Institute of Medical Sciences, Jaipur, Rajasthan-302001, India \\ ${ }^{2}$ Postgraduate Institute of Medical Sciences, Rohtak-124001, India \\ *E-mail: optomrajlvpei@gmail.com
}

\section{ARTICLE INFORMATION}

Received: July 20, 2018

Revised: September 19, 2018

Accepted: September 25, 2018

Published online: October 08, 2018

Keywords:

Fornix depth measurement, Symblepharon, Ophthalmic eye/socket, Contrast (Radiopaque tropical dye) eye drop, Radiographic image

DOI: https://doi.org/10.15415/jmrh.2018.51002

\begin{abstract}
Several methods have been publicized to measure the fornix depth but the error in the measurement makes them inconvenient for the correct diagnosis of fornix depth in the eye. In view of the cruelty of disease the precise method is needed to correctly evaluate the fornix depth measurement. In this report, a novel approach is being addressed, to solve the depth measuring issue with the logical experimental design. The explanation with the proposed hypothesis is described here with the relevant scientific approach, the emphasis of certain advantages of the present invention over the conventional measurement approaches. In this case the diagnosis and the process of diagnosis should be accurate, but in the field of ophthalmology an accurate measurement of fornix depth without committing any error was a challenging task. So far in the development of the measurement of fornix depth is concern. Currently, we discussed a novel method for the measurements of fornix depth in ophthalmic eye, which will be beneficial to get the accurate value, however it was not possible in the previously reported methods. It will have many advantages over the existing methods.
\end{abstract}

\section{Introduction}

The error in the experimental science is a lucrative task to all the scientist of the world. The minimal error in medical science plays a very important role, because of the direct dealing with the human, which some time leads to the unavoidable. Situation, hence the errors free technique a big market for the revenue generation. (Mayo, Deborah G. Error and the growth of experimental knowledge. University of Chicago Press, 1996). The medical science need a precise method to diagnose the illness, however the diagnosis is the fundamental process of the treatment, so the diagnosis should be precise.

In this case the diagnosis and the method of diagnosis should be accurate, but in the field of ophthalmology an accurate measurement of fornix depth without committing any error is a challenging task. So far in the development of the measurement of fornix depth is concern. The diagnosis of the eye is associated with many sequential eye disorders, so the proper measurement of the fornix depth is a crucial part in the ophthalmic science. Among the many eye disorders the symblepharon is a critical disorder which is the lesion of the palpebral conjunctiva of the eyelid to the bulbar conjunctiva of the eyeball, which elicit from the chemical sensation, Stevens-Johnson syndrome (SJS), ocular cicatricial pemphigoid, trachoma, herpes zoster, atopic kerato-conjunctivitis, scleroderma, or graft versus host disease and many others.

To examine the partial or complete adhesion to the fornix, it is a variable factor to correctly ascertain the depth of fornix. The error in measuring fornix depth causes various numbers of other associated factors is also there which directly or indirectly affects to cause. To combat the challenge about the precise measurement of fornix depth with more appropriate method is a mystery so far. The designing of the apparatus need a sound knowledge of normal anatomy of fornix as well as the efficacy of available anti-scarring therapies as well.

In the scientific reports several methods have been revealed to measure the fornix depth but the error in the measurement makes them inconvenient for the proper diagnosis of fornix depth in the eye. In view of the severity disease the accurate method is need to develop for the fornix depth measurement. This problem statement leads us to the development of the methods to correctly evaluate the fornix depth measurement. In this report, a novel approach is being addressed, to solve the depth measuring issue with the logical experimental design. The explanation with the 
proposed hypothesis is described here with the relevant scientific approach with the emphasis of certain advantages of the present invention over the conventional measurement approaches

In the present invention, useful method of fornix depth measurement has been done, which will dominate the regular use of custom-designed device (Polymethylmethacrylate) for fornix depth measurer (FDM). It will be essential tool to evaluate the anti-scarring therapy, need objective evaluation of scarring plus understanding of normal fornix structure. In conventional method, there is the probability of error in the value of the normal fornix depth (FD), however there are some studies, which are investigating normal conjunctival FD by the different methods.

We designed and demonstrated a novel method which will be based objective measurements and beneficial to get the accurate value of fornix depth in ophthalmic socket, however it was not possible with the others conventional methods; due to presence of the manually handled embedded ruler.

\section{Field of the Invention}

The present invention proposed a novel method for the relation to quantify the amount of conjunctival fibrosis on behalf of records to evolution in conjunctival scarring disease, based on objective measurement of superior plus inferior conjunctival fornix depth and knowledge of standard fornix anatomy, was a clinical challenge.

\section{Summary of Invention}

To assessing anti-scarring treatments have need of objective evaluation of scarring, also understanding of standard fornix anatomy in normal ophthalmic socket, Objective evaluation of improvement of conjunctival cicatrization, plus the awareness of standard conjunctival fornix depth values, is a necessary pre-requirement while assessing the worth of anti-scarring treatments in the classical scarring disorder, ocular mucous membrane pemphigoid, it has been detected that scarring can progress despite apparent clinical control of inflammation.

Early recognition of any appearance of progressive cicatrization is the solution in the direction of managing of conjunctival scarring disorders. Clinically, single have get to look for increased conjunctival shrinkage or development of symblepharon, Objective dimension of conjunctival fornix depth, with awareness of probable standard range of values, would agree to prior recognition of conjunctival fornix reduction (Foster phase II), in an ideal world before the progress of (Foster phase III) symblepharon.
But now in this invention \& a novel method of fornix depth measurement in ophthalmic eye, with the use of Contrast (Radiopaque tropical dye) eye drop in fornix \& take radiographic image with the computed tomography (CT) scan. It will be measure the fornix depth in radiograph and useful for objective evaluating anti-scarring therapies of the fornix.

\section{Detailed Description of the Invention}

The contrast (Radiopaque tropical dye) eye drop creates the boundaries in the fornix, which is easily recognized in the radiograph.

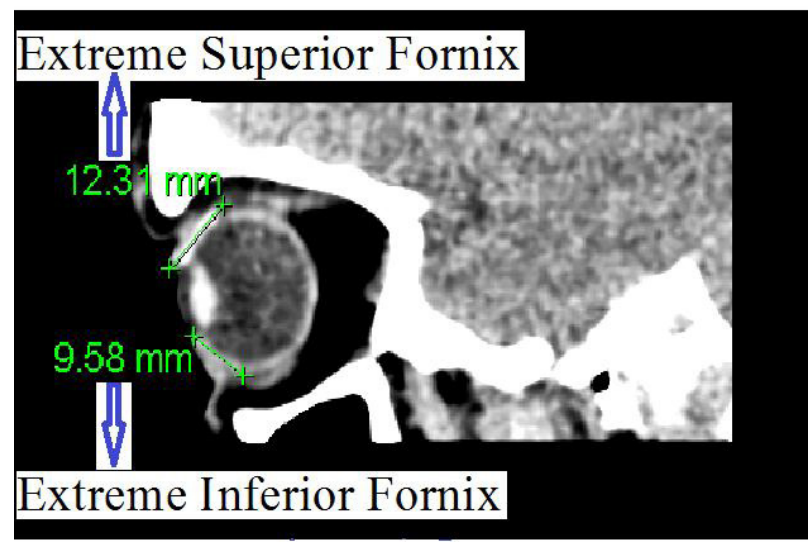

Figure 1:

Radiograph: The present (new) invention, the method of fornix depth measurement of ophthalmic eye

The radiograph image will help to measure the fornical depth in deferent direction with the use of the computed tomography (CT) scan (Figure 1).

\subsection{Conjunctival troubles}

Symblepharon: This occurs while adhesions start among the bulbar and palpebral conjunctiva. This can occur in a number of situations be fond of burn injury, with recurring pterygia, in Stevens-Johnson syndrome, etc.

The quantifying amount of conjunctival fibrosis used for records of progress in conjunctival scarring disease is a medical challenge. The purpose of this, new present invention will be able to resolve the current problem by a non-invasive radiographic method. It will define the limit of average conjunctival fornix depth/ structure, which may be helpful to normative records of superior and inferior fornix depths (FDs) to assess variability in deferent gauging of fornix depth, area and fornix intercanthal distance (FICD) in a normal people and it will also provide 
the information about the effect of age and sex. This estimation method may be beneficial in future for assessing the cruelty of symblepharon plus determination of the postsurgical prediction. Conjunctival fornical foreshortening is significant in ascertaining phase of the progressive cicatrizing conjunctivitis (PCC) disease, Although different tools have been identified so far but they are not precise as much as our present invention.

\section{Conclusion}

Here, we discussed a novel method for the measurements of fornix depth in ophthalmic eye, which will be beneficial to get the accurate value, however it was not possible in the previously reported methods. It will have many advantageous over the existing methods.

\section{References}

Barabino, S., et al. (2003). "Role of amniotic membrane transplantation for conjunctival reconstruction in ocular-cicatricial pemphigoid." Ophthalmology 110(3): 474-480. https://doi.org/10.1016/S0161-6420(02)01892-4

Betharia, S. and H. Kumar (1988). "Surgical management of contracted socket." Indian journal of ophthalmology 36(2): 79 .

Chan, L. S., et al. (2002). "The first international consensus on mucous membrane pemphigoid: definition, diagnostic criteria, pathogenic factors, medical treatment, and prognostic indicators." Archives of dermatology 138(3): 370-379.

https://doi.org/10.1001/archderm.138.3.370

Chang, J. H. and P. J. McCluskey (2005). "Ocular cicatricial pemphigoid: manifestations and management." Current allergy and asthma reports 5(4): 333-338. https://doi.org/10.1007/s11882-005-0078-9

Elder, M. J., et al. (1996). "Progression of disease in ocular cicatricial pemphigoid." British journal of ophthalmology 80(4): 292-296.

https://doi.org/10.1136/bjo.80.4.292

Faraj, H. G. and T. Hoang-Xuan (2001). "Chronic cicatrizing conjunctivitis." Current opinion in ophthalmology 12(4): 250-257.

https://doi.org/10.1097/00055735-20010800000003

Foster, J. A., et al. (1999). "Reconstruction of the irradiated contracted socket with an expanded superficial temporalis fascial flap." American journal of ophthalmology 127(5): 621-622.

https://doi.org/10.1016/S0002-9394(98)00429-2
Grob, S., et al. (2016). "Dry Eye Therapy." Ophthalmic Disease Mechanisms And Drug Discovery: 97. https://doi.org/10.1142/9789814663076_0005

Honavar, S. G., et al. (2000). "Amniotic membrane transplantation for ocular surface reconstruction in Stevens-Johnson syndrome." Ophthalmology 107(5): 975-979. https://doi.org/10.1016/S0161-6420(00)00026-9l

Hossain, P. (2011). The evil curse of ocular pemphigoid, Nature Publishing Group. https://doi.org/10.1038/eye.2011.181

Jutley, G., et al. (2016). "Upper and lower conjunctival fornix depth in healthy white caucasian eyes: a method of objective assessment." Eye 30(10): 1351. https://doi.org/10.1038/eye.2016.128

Kakizaki, H., et al. (2006). "Microscopic anatomy of Asian lower eyelids." Ophthalmic Plastic \& Reconstructive Surgery 22(6): 430-433. https://doi.org/10.1097/01.iop. 0000242182.96161.78

Kawakita, T., et al. "Measurement of fornix depth and area: a novel method of determining the severity of fornix shortening." Eye 23.5 (2009): 1115. https://doi.org/10.1038/eye.2008.205

Khan, I. J., et al. (2014). "Defining the limits of normal conjunctival fornix anatomy in a healthy South Asian population." Ophthalmology 121(2): 492-497. https://doi.org/10.1016/j.ophtha.2013.09.033

Kim, C. Y., et al. (2014). "Postoperative outcomes of anophthalmic socket reconstruction using an autologous buccal mucosa graft." Journal of Craniofacial Surgery 25(4): 1171-1174. https://doi.org/10.1097/SCS.0000000000000807

Kim, E. C. and C. S. Foster (2006). "Immunomodulatory therapy for the treatment of ocular inflammatory disease: evidence-based medicine recommendations for use." International ophthalmology clinics 46(2): 141-164. https://doi.org/10.1097/00004397-20060462000013

Klein, M., et al. (2000). "Reconstruction of the contracted ocular socket with free full-thickness mucosa graft." International journal of oral and maxillofacial surgery 29(2): 96-98. https://doi.org/10.1016/S0901-5027(00)80004-1

Kumar, R., et al. (2018). "An opinion: fornix depth measurement in ophthalmic socket." JETIR1810016, 23495162 .

Lukats, O. (2002). "Contracted anophthalmic socket repair." Orbit (Amsterdam, Netherlands) 21(2): 125-130. 
Mavrikakis, I., et al. (2006). "Surgical management of the severely contracted socket following reconstruction." Orbit 25(3): 215-219. https://doi.org/10.1080/01676830600671383

Meller, D. and S. C. Tseng (1998). "Conjunctivochalasis: literature review and possible pathophysiology." Survey of ophthalmology 43(3): 225-232. https://doi.org/10.1016/S0039-6257(98)00037-X

Mondino, B. J. and S. I. Brown (1981). "Ocular cicatricial pemphigoid.” Ophthalmology 88(2): 95-100. https://doi.org/10.1016/S0161-6420(81)35069-6

Mondino, B. J. and S. I. Brown (1983). "Immunosuppressive therapy in ocular cicatricial pemphigoid." American journal of ophthalmology 96(4): 453-459. https://doi.org/10.1016/S0002-9394(14)77908-5

$\mathrm{Mu}$, X., et al. (1999). "Surgical reconstruction of the contracted eye socket and orbitozygomatic hypoplasia in a one-stage operation." Plastic and reconstructive surgery 103(2): 487-493.

https://doi.org/10.1097/00006534-19990200000019

Paris, G. L. and W. G. Spohn (1983). "Repair of the contracted socket using RTV silicone as a stent for mucosal grafting." Ophthalmic Surgery, Lasers and Imaging Retina 14(8): 671-674.

Poonyathalang, A., et al. (2005). "Reconstruction of contracted eye socket with amniotic membrane graft." Ophthalmic Plastic \& Reconstructive Surgery 21(5): 359-362. https://doi.org/10.1097/01.iop.0000179378.97762.c7

PUTTERMAN, A. M. (1985). "Reconstruction of the contracted ocular socket." Australian and New Zealand journal of ophthalmology 13(2): 171-178.

https://doi.org/10.1111/j.1442-9071.1985.tb00418.x

Radford, C., et al. (2008). "Presentation, Management and Disease Progression in Early Ocular Mucous Membrane Pemphigoid." Investigative Ophthalmology \& Visual Science 49(13): 802-802.

Rauz, S., et al. (2005). "Evaluation of mucous membrane pemphigoid with ocular involvement in young patients." Ophthalmology 112(7): 1268-1274. https://doi.org/10.1016/j.ophtha.2005.01.039

Reeves, G. M., et al. (2012). "Ocular and oral grading of mucous membrane pemphigoid." Graefe's Archive for Clinical and Experimental Ophthalmology 250(4): 611-618.https://doi.org/10.1007/s00417-0111853-z

Rose, G. E. (2004). "The giant fornix syndrome: an unrecognized cause of chronic, relapsing, grossly purulent conjunctivitis." Ophthalmology 111(8): 1539-1545.

https://doi.org/10.1016/j.ophtha.2004.01.037

Rose, G. E. (2005). “The Giant Fornix Syndrome: author reply." Ophthalmology 6(112): 1173.

https://doi.org/10.1016/j.ophtha.2004.12.003

Rowsey, J. J., et al. (2004). "A New Method for Measuring Progression in Patients With Ocular Cicatricial Pemphigoid." Archives of Ophthalmology 122(2): 179-184. https://doi.org/10.1001/archopht.122.2.179

Sanfilippo, P. and G. Lee (2003). "Ocular cicatricial pemphigoid." Clinical and Experimental Optometry 86(1): 47-50.

https://doi.org/10.1111/j.1444-0938.2003.tb03057.x

Saw, V. P., et al. (2008). "Immunosuppressive therapy for ocular mucous membrane pemphigoid: strategies and outcomes." Ophthalmology 115(2): 253-261. e251. https://doi.org/10.1016/j.ophtha.2007.04.027

Saw, V. P., et al. (2011). "Profibrotic phenotype of conjunctival fibroblasts from mucous membrane pemphigoid." The American journal of pathology 178(1): 187-197. https://doi.org/10.1016/j.ajpath.2010.11.013

Schwab, I. R., et al. (1992). "Foreshortening of the inferior conjunctival fornix associated with chronic glaucoma medications." Ophthalmology 99(2): 197-202. https://doi.org/10.1016/S0161-6420(92)32001-9

Sherratt, M. J. (2009). "Tissue elasticity and the ageing elastic fibre.” Age 31(4): 305-325. https://doi.org/10.1007/s11357-009-9103-6

Shi, Y., et al. (2018). "Efficacy and adverse reactions of methotrexate in the treatment of ocular cicatricial pemphigoid: A case series study." Medicine 97(38). https://doi.org/10.1097/MD.0000000000012338

Solomon, A., et al. (2003). "Amniotic membrane transplantation for reconstruction of the conjunctival fornices." Ophthalmology 110(1): 93-100. https://doi.org/10.1016/S0161-6420(02)01441-0

Tepelus, T. C., et al. (2017). "Characterization of corneal involvement in eyes with mucous membrane pemphigoid by in vivo confocal microscopy." Cornea 36(8): 933-941. https://doi.org/10.1097/ICO.0000000000001201

Tseng, S. C., et al. (2005). "Intraoperative mitomycin C and amniotic membrane transplantation for fornix reconstruction in severe cicatricial ocular surface diseases." Ophthalmology 112(5): 896-903. e891. https://doi.org/10.1016/j.ophtha.2004.11.041 
van den Bosch, W. A., et al. (1999). "Topographic anatomy of the eyelids, and the effects of sex and age." British journal of ophthalmology 83(3): 347-352.

https://doi.org/10.1136/bjo.83.3.347

Williams, G., et al. (2008). "Presentation and disease progression in established ocular mucous membrane pemphigoid." Investigative Ophthalmology \& Visual Science 49(13): 803-803.

Williams, G. P., et al. (2011). "Evaluation of early and late presentation of patients with ocular mucous membrane pemphigoid to two major tertiary referral hospitals in the United Kingdom.” Eye 25(9): 1207. https://doi.org/10.1038/eye.2011.175

Williams, G. P., et al. (2011). "Validation of a fornix depth measurer: a putative tool for the assessment of progressive cicatrising conjunctivitis." British Journal of Ophthalmology 95(6): 842-847.

https://doi.org/10.1136/bjo.2010.188011 